\title{
DESAFIOS E OPORTUNIDADES PARA MANUTENÇÃO DA ISO 9001/2015 EM UMA EMPRESA DE MINERAÇÃO DO VALE DO JEQUITINHONHA
}

\author{
CHALLENGES AND OPPORTUNITIES FOR THE MAINTAINING OF ISO 9001/2015 AT A VALE \\ DO JEQUITINHONHA MINING COMPANY
}

\author{
Recebido em 05.05.2020 Aprovado em 31.07.2020 \\ Avaliado pelo sistema double blind revien \\ DOI: https://doi.org/10.32888/cge.v8i2.42560
}

\begin{abstract}
Nilton Ramalho Siqueira
nilton10ramalho@gmail.com

Programa de Graduação em Administração/Instituto Federal do Norte de Minas Gerais - Araçuaí/MG, Brasil https://orcid.org/0000-0002-1696-0167
\end{abstract}

Nayara Teixeira dos Santos

nayara.santos@ifnmg.edu.br

Programa de Graduação em Administração/Instituto Federal do Norte de Minas Gerais - Araçuaí/MG, Brasil https://orcid.org/0000-0001-6496-7622

\author{
Ismael Mendes dos Santos Júnior \\ ismael.junior@ifnmg.edu.br \\ Programa de Graduação em Administração/Instituto Federal do Norte de Minas Gerais - Araçuaí/MG, Brasil \\ https://orcid.org/0000-0001-9412-6023
}

Lucas Pazolini Dias Rodrigues

lucas.rodrigues@ifnmg.edu.br

Programa de Graduação em Administração/Instituto Federal do Norte de Minas Gerais - Araçuaí/MG, Brasil https://orcid.org/0000-0001-8931-525X

\section{Resumo}

O objetivo desse trabalho foi identificar os desafios e oportunidades para manutenção do processo de gestão da qualidade ISO 9001/2015 em uma empresa de mineração localizada na região do Vale do Jequitinhonha. Foi aplicado um questionário estruturado a cinquenta funcionários da empresa. O desenvolvimento desta pesquisa permitiu compreender como a empresa certificada pelo ISO 9001, obtém vantagens e enfrenta seus desafios. Foi possível constar que os maiores desafios encontrados pela empresa para a manutenção da norma ISO 9001 de 2015, foram: resistência a mudanças por parte dos funcionários; baixa escolaridade dos funcionários; burocratização; treinamento da equipe: ansiedade por resultados.

Palavras-chave: Desafios. Manutenção ISO 9001. Mineração.

\begin{abstract}
The objective of this work was to identify the challenges for maintaining the ISO 9001/2015 quality management process in a company located in the Vale do Jequitinhonha region. For this, one semi-structured questionnaire was applied to fifty company employees. Besides, the development of this research has allowed us to understand how the certified company by ISO 9001 obtains advantages and confronts its challenges. Finally, it was noted that the biggest challenges were: resistance to change by employees; low education of employees; bureaucratization; team training: anxiety about results.
\end{abstract}

Keywords: Challenges. Maintenance of ISO 9001. Mining. 


\section{Introdução}

"O conceito da qualidade envolve múltiplos elementos, com diferentes níveis de importância. Centrar atenção exagerada em algum deles ou deixar de considerar outros pode fragilizar estrategicamente a empresa" (Paladini, 2012, p. 7). Por isso, para Kotler e Armstrong (2003), o nível de qualidade que se deseja alcançar num determinado produto necessita estar em consonância com o mercado-alvo que se quer atingir.

Um Sistema de Gestão da Qualidade é uma ferramenta gerencial que proporciona às organizações uma estrutura necessária para o gerenciamento dos processos e atividades com vistas à melhoria constante do trabalho oferecido (Campos, 2009). Para nortear a implantação de tais sistemas, foram criadas instituições normatizadoras que permitiram a formalização de padrões de qualidade por meio de documentos normativos.

A organização sem fins lucrativos International Organization for Standardization (ISO), em português Organização Internacional de Normalização, criada em 1947 em Londres, apresenta um modelo de um Sistema de Gestão da Qualidade baseado em processos, cuja meta é a melhoria contínua. Os processos são descritos em uma série de normas técnicas que, no Brasil, foram traduzidas e adaptadas pela Associação Brasileira de Normas Técnicas (ABNT).

A ISO 9001:2015 é utilizada por organizações que desejam comprovar sua capacidade de fornecer produtos e serviços que atendem às necessidades de seus clientes e requisitos legais e regulatórios aplicáveis (ABNT, 2015). Essas organizações podem ter diferentes finalidades, sejam elas organizações sem fins lucrativos, empresas prestadoras de serviços ou indústrias. Para obter a certificação ISO é necessário que a empresa passe pelo processo de certificação. Após todo o processo de implementação do sistema de gestão e a certificação, o grande desafio é a manutenção desse sistema. Uma vez que o acompanhamento deve ser contínuo, a manutenção do sistema de gestão torna-se um item crítico (Tanabe \& Souza, 2006). A partir do momento da certificação a empresa deve entender que deve possuir capacidade de evoluir, pois a gestão da qualidade é ampla e progressiva, sendo a organização responsável pelo envolvimento no processo no decorrer do tempo. Para isso é necessário monitoramento, avaliação e retroalimentação. Desse modo, a qualidade não pode ser vista como algo imutável, mas como um processo em constante evolução (Paladini, 2012).

Diante do apresentado, o objetivo geral deste estudo foi identificar os desafios e oportunidades para manutenção do Sistema de Gestão da Qualidade ISO 9001/2015 em uma empresa de mineração localizada na região do Vale do Jequitinhonha no estado de Minas Gerais. Para tal, teve como objetivos específicos: i) entender o funcionamento do Sistema de Gestão de Qualidade na empresa em estudo; ii) avaliar as motivações e desafios na condução de uma gestão da qualidade pautada nos requisitos da ISO 9001; iii) analisar as vantagens obtidas pela empresa ao adotar a ISO 9001. A escolha deste objeto de estudo se deve principalmente pelo minério ser um importante recurso, abundante no território brasileiro, e em particular na mesorregião onde a empresa se situa. O Brasil detém um dos maiores patrimônios minerais do mundo e é um produtor e exportador de minérios de alta qualidade (IBRAM, 2011). Além disso, as mineradoras como as demais empresas, também passam pelo processo de certificação ISO 9001.

Esse trabalho se justifica, no sentido de compreender melhor os desafios e oportunidades para manter o Sistema de Gestão da Qualidade, já que a empresa faz parte de uma região que responde por $85 \%$ da produção de lítio no Brasil. O lítio é chamado de "petróleo branco" e tem sido usado como argumento para a transformação do "Vale da Miséria", como popularmente é denominado o Vale do Jequitinhonha (Lage, 2019). Neste sentido, a realização deste estudo em uma empresa de mineração é inédita e representativa por auxiliar na manutenção da garantia da qualidade na produção de um componente tão importante para a sociedade brasileira e para a mudança socioeconômica da região do Vale do Jequitinhonha. 


\section{Referencial Teórico}

\section{Sistema de Gestão da Qualidade}

O Sistema de Gestão da Qualidade (SGQ) é um conjunto de elementos inter-relacionados que estabelecem políticas e objetivos no que diz respeito à qualidade (ABNT, 2000). O SGQ foi criado para gerir e garantir a qualidade, os recursos necessários, os procedimentos operacionais e responsabilidades, garantindo o fornecimento de produtos e serviços (Bento \& Lucena 2017). Essas políticas, objetivos e procedimentos são especificados pelas normas técnicas.

No Brasil, estas normas que compõem o SGQ são determinadas pela sigla NBR ISO e são criadas e gerenciadas pela Associação Brasileira de Normas Técnicas (ABNT). As principais são a 9000, 9001 e 9004:

- $\quad$ ABNT NBR ISO 9000 - Sistema de Gestão da Qualidade (Fundamentos e Vocabulário) Documento que contém todos os termos utilizados no sistema;

$-\quad \mathrm{ABNT}$
obter a certificação;

- $\quad$ ABNT NBR ISO 9004 - Gestão para o Sucesso Sustentado de uma Organização (Uma abordagem de Gestão da Qualidade) - Documento com instruções para implantar o Sistema de Gestão da Qualidade.

Uma das principais referências de qualidade para as empresas é a NBR ISO 9001, o padrão ISO 9001, criado pela ISO, que estabelece critérios mínimos a serem atendidos pelas empresas na implementação do SGQ, visando à padronização e à garantia da qualidade nas relações de fornecimento de mercadorias e serviços entre organizações (Marin, 2012).

A Implantação de um sistema de qualidade traz vários benefícios, dentre eles há uma melhoria da capacitação técnica do pessoal, aumentando a confiabilidade dos resultados emitidos. Além disso, há outros benefícios, como: facilitar negociação comercial, reduzir riscos, desperdícios e custos (Barbosa, 2013).

\section{Implantação da Norma NBR ISO 9000}

A implantação de um sistema de qualidade é um processo de aprendizado, não deve ter regras muito rígidas e deve ser adaptado às necessidades da empresa (Campos, 1992). A literatura apresenta diferentes modelos para a implantação. Para Fortes (2012), o modelo de implementação da norma consiste de cinco etapas, cujo fluxo é ilustrado na Figura 1.

Figura 1 - Etapas da Implementação do Sistema de Gestão da qualidade

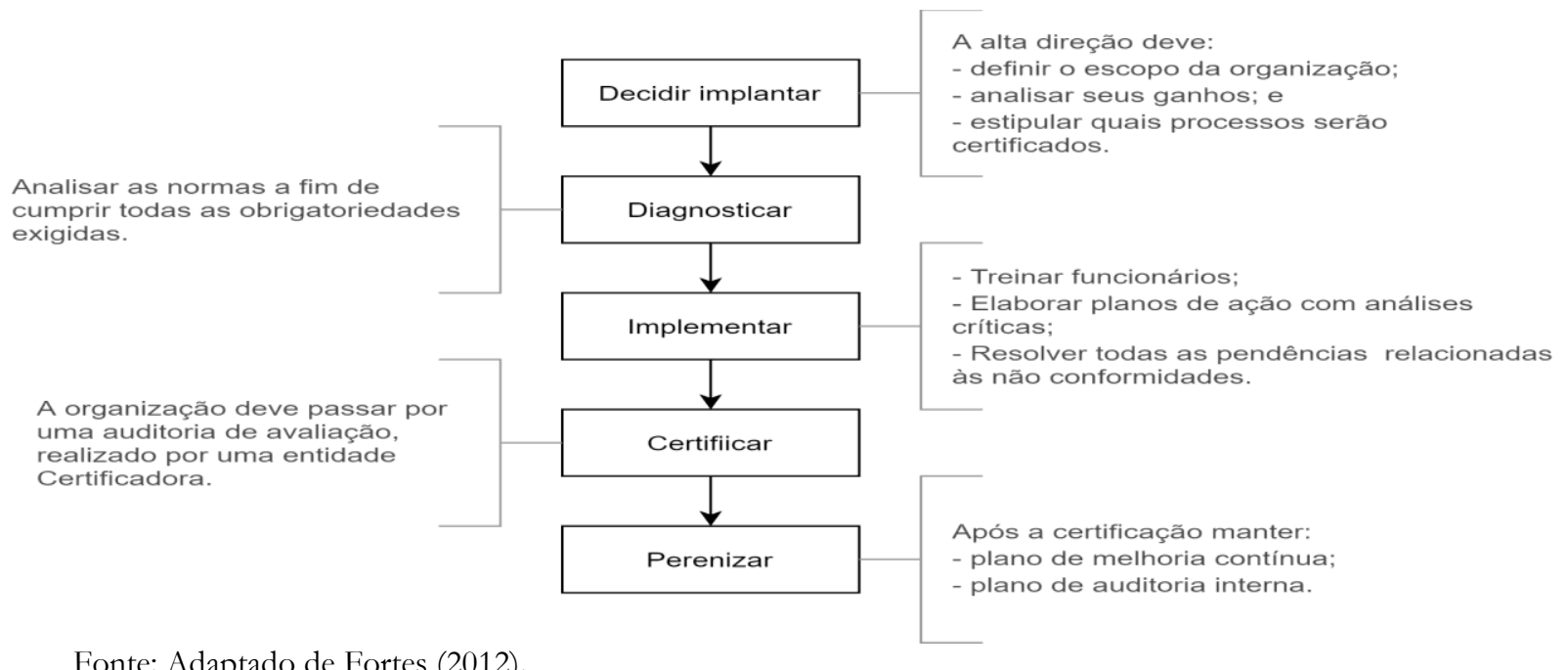

Fonte: Adaptado de Fortes (2012). 
Para o autor, ao decidir implantar a norma, a alta direção deve definir o escopo da organização, analisar seus ganhos e estipular quais processos deve ser certificados de modo a agregar valor ao negócio. Após decidir implantar, vem o processo de diagnosticar, que consiste em analisar as normas buscando alcançar a conformidade, ou seja, cumprir todas as obrigatoriedades exigidas.

Implementar é a etapa mais longa do processo. Nela deve ser feito o treinamento dos funcionários, devem ser elaborados planos de ação com análises críticas realizadas pela alta direção e também devem ser resolvidas todas as pendências relacionadas às não conformidades. Na penúltima etapa, a de certificação, a organização deve passar por uma auditoria de avaliação, realizada por uma entidade certificadora. Finalmente, após a certificação, o SGQ deve ser mantido por meio de contínua análise crítica da alta direção, bem como pelos planos de melhoria contínua e de auditoria interna, o que traz diversos desafios para a organização.

\section{Desafios para a manutenção do Sistema de Gestão da Qualidade}

A certificação não é suficiente para garantir a satisfação dos clientes e manter a competitividade da empresa, em um ambiente globalizado e altamente competitivo (Cota \& Freitas, 2013). A maioria das organizações vê como grande desafio as certificações, porém a conquista do Certificado ISO 9001 não é o fim de um trabalho, mas início de uma jornada pautada principalmente pela disciplina (Rigoni, 2018).

A certificação possui um prazo de validade de três anos. Neste período, a empresa passará por auditoria anual de manutenção da certificação (recertificação) para verificar a evolução do sistema de gestão da qualidade e quais foram as melhorias realizadas nesse período (ABNT, 2010). O processo de auditoria consiste em analisar documentos, registros, apresentações de fatos ou outras informações e depois comparar com uma norma ou requisito pré-estabelecido (Paulista \& Turrioni, 2008).

Existem dois tipos de auditoria: interna e externa. A auditoria interna é realizada pela própria empresa para auditar seu próprio sistema. O objetivo é contribuir para a melhoria do SGQ e o seu desempenho, verificando a conformidade dos processos com os requisitos da norma (Bonato \& Caten, 2013).

Já as auditorias externas são realizadas por organizações de auditoria independente, tais como organizações que provêem certificados ou registros de conformidade com os requisitos da NBR ISO 9001(NBR, 2000). Para alcançar os objetivos propostos pela gestão da qualidade é necessário que as organizações entendam e pratiquem a melhoria contínua, atuando em consonância com o perfil do consumidor cada vez mais consciente do seu poder de influenciar as diretrizes das organizações, demandando ações voltadas para o desenvolvimento de processos que assegurem inovação, qualidade e sustentabilidade (Cota \& Freitas, 2013).

\section{Procedimentos metodológicos}

Esta pesquisa é classificada com base nos seus fins, como descritiva, que para Gil (2002, p. 42) "tem por objetivo primordial a descrição das características de determinada população ou fenômeno, ou, então, o estabelecimento de relações entre as variáveis". De acordo com Markoni e Lakatos (2002, p. 20), a pesquisa descritiva "aborda quatro aspectos: descrição, registro, análise e interpretação de fenômenos atuais, objetivando o seu funcionamento no presente".

Quanto aos seus procedimentos técnicos pode-se classificar esta pesquisa como documental e estudo de caso. Documental porque se utilizou de documentos cedidos pela empresa, tais como organograma institucional, fluxograma do processo produtivo e manual da qualidade. A pesquisa documental consiste num exame de diversos materiais, buscando interpretações ou informações complementares (Guba \& Lincoln, 1981).

Já o estudo de caso, justifica-se por se tratar de um estudo específico em uma organização. Para Yin (2001, p.43) "o estudo de caso é uma investigação empírica de um fenômeno contemporâneo dentro de um contexto da vida real, sendo que os limites entre o fenômeno e o contexto não está claramente definido". 
A abordagem dessa pesquisa foi do tipo qualitativa. Na coleta dos dados foi aplicado um questionário estruturado, adaptado de Lima (2018), a 50 funcionários da empresa, junto à equipe responsável pela Gestão da Qualidade, supervisores, encarregados e colaboradores operacionais dos setores de Apoio Geral, Manutenção, Mina e Produção.

O questionário é uma técnica utilizada quando se pretende obter o máximo de dados possíveis sobre um específico tema e também obter um maior detalhamento do assunto ali exposto (Minayo, 2010).

O questionário continha 21 perguntas, sendo quatro abertas voltadas à identificação do funcionário e 17 fechadas, utilizando a escala do tipo Likert. O período de coleta de dados aconteceu entre os meses de agosto e novembro de 2019. Após a coleta, os dados foram codificados e convertidos em escalas nominais e ordinais e tabulados no Microsoft Excel 2013.

Para alcançar os objetivos propostos, dispôs-se da análise dos resultados a partir da estatística descritiva, que segundo Reis (1996), consiste na coleta, análise e interpretação de dados numéricos a partir de ferramentas como tabelas, figuras e indicadores. Devido à natureza qualitativa dos dados obtidos por meio dos instrumentos de coleta (questionário estrutura e documentos), buscou-se primeiramente sumarizar os dados numericamente (contagem e proporções) para a partir de então apresentar panoramas e realizar inferências.

\section{Empresa de Estudo}

A empresa apresenta capital 100\% nacional, sendo pioneira na lavra subterrânea do minério que produz, assim como no beneficiamento do mineral. Fundada em 1985, objetivando atender ao mercado interno e externo, está em operação desde 1991, com um quadro de aproximadamente 100 colaboradores.

A unidade de mineração contempla os processos estratégicos, táticos e operacionais para a produção mineral da empresa, abrangendo desde planejamento estratégico pela alta direção para atendimento das demandas de mercado e clientes, planejamento da produção, incluindo o dimensionamento da lavra e beneficiamento mineral, assim como as áreas de apoio, sendo administrativos, manutenção e almoxarifado.

Os marcos históricos da empresa são:

- $\quad$ 1991: Início das operações na unidade de mineração.

- $\quad$ 1992: Início da comercialização dos produtos.

- $\quad$ 1998: Reestruturação da unidade de beneficiamento mineral.

- 2005 e 2015: Modernização da produção com aquisição de novos equipamentos de perfuração.

- $\quad$ 2014: Certificação ABNT NBR ISO 9001

- 2016: Atinge capacidade atual de produção.

Para melhoria sistêmica da gestão organizacional, a empresa implantou a norma ABNT NBR ISO 9001 (Sistema de gestão da qualidade - Requisitos), sendo realizada a certificação por organismo certificador em maio de 2014, tendo o SGQ atual da organização cinco anos de implementação.

\section{Apresentação e análise dos resultados}

No que se refere ao perfil dos respondentes, constatou-se que estes possuíam idade entre 29 a 56 anos. Quanto ao grau de escolaridade (Gráfico 1), observa-se que a maioria possui até o ensino médio e que $42 \%$ possuem apenas ensino fundamental, o que demonstra uma baixa escolaridade dos funcionários. Depexe e Paladini (2007), em seu estudo com construtoras concluíram que o baixo nível de escolaridade na implantação e certificação de sistemas de gestão da qualidade afeta de forma diferente as empresas de um mesmo segmento. Algumas empresas encontram dificuldades em relação ao baixo nível de escolaridade dos seus funcionários e outras não. 
As empresas que não possuem dificuldades com o baixo nível de escolaridade adotam programas de treinamento para diminuir essa lacuna.

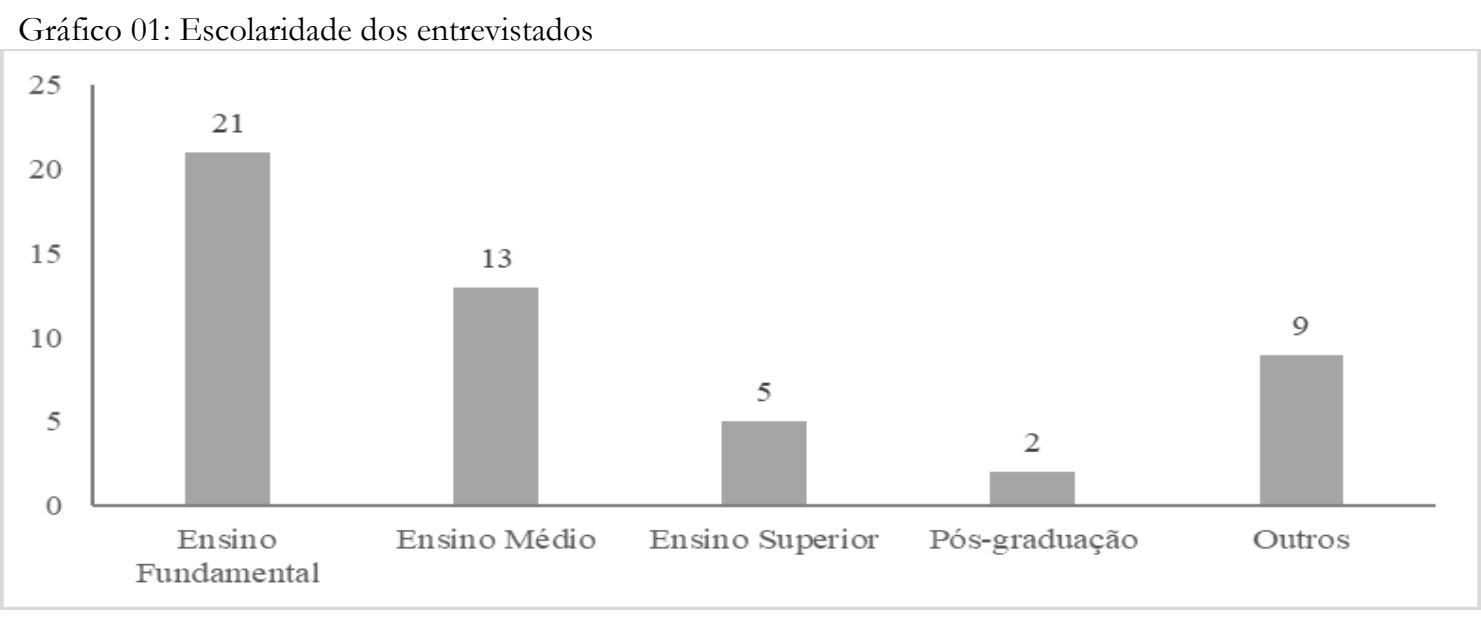

Fonte: Elaborado pelos autores, 2019.

Constatou-se que $68 \%$ dos funcionários que responderam ao questionário têm mais de cinco anos de tempo de trabalho (Gráfico 2). Entre eles, verificou-se que existem funcionários que trabalham na empresa desde a primeira certificação, tendo alguns funcionários alcançado os trinta anos de serviço (12\%).

Gráfico 2 - Tempo de serviço dos entrevistados

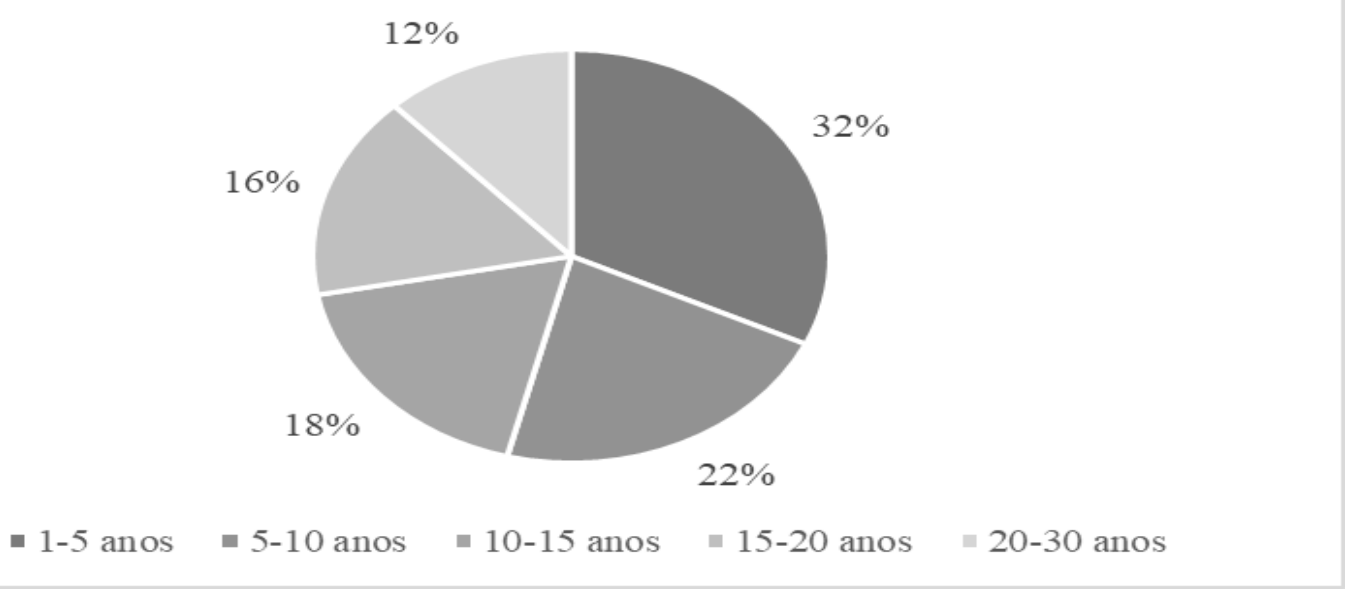

Fonte: Elaborado pelos autores, 2019.

No que concerne ao SGQ da empresa, os funcionários afirmaram, por unanimidade, que conhecem a ISO 9001 e que a empresa faz reuniões para auditoria interna e para melhoria dos processos. Eles relataram que há reuniões semanais $(82 \%)$, mensais $(14 \%)$ e anuais na empresa (4\%). As respostas evidenciam o conhecimento por parte dos funcionários da ISO 9001 e sugerem seu envolvimento no processo. Segundo Stoner (1992), a busca coletiva de soluções para problemas aumenta as chances de êxito na sua implementação, ao incluir no processo de tomada de decisão todas as pessoas envolvidas. Quando as pessoas ajudam a resolver um problema, elas vêem a solução também como sua e têm um interesse pessoal em fazer com que ela dê certo. Além de proporcionar o alinhamento das melhorias e rotinas processuais, a realização de reuniões gerenciais periódicas permite o acompanhamento dos resultados da produção, com análise da relação planejada versus realizado, assim como possíveis desvios, com direcionamentos para a tomada de decisão. Os resultados contrariam Ávila e Stecca (2015) e Depex e Paladini (2007), que apresentam como maiores desafios na implementação e manutenção da IS $\mathrm{O}$, o envolvimento dos funcionários no processo. 
Quanto ao apoio técnico (Tabela1), esse questionamento foi feito relacionado ao tipo de suporte técnico recebido pelos funcionários, como manutenção, revisões, regulagens, calibrações, reparos/consertos, entre outros. Foi possível constatar que $76 \%$ dos funcionários apresentaram-se satisfeitos com o apoio que vem recebendo da empresa para manutenção da gestão da qualidade.

Tabela 1 - Falta de apoio técnico

\begin{tabular}{c|c|c|c|c}
\hline 1 & 2 & 3 & 4 & 5 \\
$\begin{array}{c}\text { Discordo } \\
\text { Completamente }\end{array}$ & Discordo & $\begin{array}{c}\text { Nem Concordo } \\
\text { Nem Discordo }\end{array}$ & Concordo & $\begin{array}{c}\text { Concordo } \\
\text { Completamente }\end{array}$ \\
\hline 22 & 18 & 4 & 5 & 1 \\
$40 \%$ & $36 \%$ & $8 \%$ & $10 \%$ & $2 \%$ \\
\hline
\end{tabular}

Fonte: Elaborado pelos autores, 2019.

Em se tratando de desinteresse em nível gerencial (Tabela 2), é possível dizer que os funcionários se mostram mais satisfeitos em comparação ao Apoio Técnico (Tabela 1), uma vez que apresentou maior porcentagem de satisfação (84\%). Ressalva-se que deve se levar em consideração que o questionário foi aplicado por um funcionário da empresa. É possível que nessa questão os funcionários tenham ficado receosos com as respostas, uma vez que o questionário foi aplicado por um colega de trabalho. Todavia, este resultado evidencia os resultados de Depex e Paladini (2007), ao identificar a cultura organizacional e resistências a mudanças por parte dos funcionários como dificuldades. Ou seja, torna-se evidente que não existe desinteresse em nível gerencial.

Tabela 2 - Desinteresse do nível gerencial

\begin{tabular}{c|c|c|c|c}
\hline 1 & 2 & 3 & 4 & 5 \\
$\begin{array}{c}\text { Discordo } \\
\text { Completamente }\end{array}$ & Discordo & $\begin{array}{c}\text { Nem Concordo } \\
\text { Nem Discordo }\end{array}$ & Concordo & $\begin{array}{c}\text { Concordo } \\
\text { Completamente }\end{array}$ \\
\hline 21 & 21 & 3 & 4 & 1 \\
$42 \%$ & $42 \%$ & $6 \%$ & $8 \%$ & $2 \%$ \\
\hline
\end{tabular}

Fonte: Elaborado pelos autores, 2019.

Os resultados de insatisfação são relativamente parecidos, o que se explica pelo fato de que o apoio técnico passa pelo apoio gerencial dentro da empresa e são funções que se complementam.

Foi possível constatar que os funcionários da empresa têm dificuldade para lidar com mudanças (Tabela 3), já que $66 \%$ responderam ao questionário dizendo que existe resistência. Isso pode estar relacionado ao grau de escolaridade dos funcionários, uma vez que, dentre os entrevistados, a maioria (42\%) apresentou apenas ensino fundamental. Tanabe e Sousa (2006) relataram em seu trabalho que quanto mais baixo o nível de escolaridade dos funcionários da empresa, maior é a resistência às mudanças.

Tabela 3 - Resistência à mudança por parte dos funcionários

\begin{tabular}{c|c|c|c|c}
\hline 1 & 2 & 3 & 4 & 5 \\
$\begin{array}{c}\text { Discordo } \\
\text { Completamente }\end{array}$ & Discordo & $\begin{array}{c}\text { Nem Concordo } \\
\text { Nem Discordo }\end{array}$ & Concordo & $\begin{array}{c}\text { Concordo } \\
\text { Completamente }\end{array}$ \\
\hline 7 & 14 & 6 & 14 & 19 \\
$14 \%$ & $8 \%$ & $12 \%$ & $28 \%$ & $38 \%$ \\
\hline Fonte: Elaborado pelos autores, 2019.
\end{tabular}

Fonte: Elaborado pelos autores, 2019. 
O resultado também pode ter sido influenciado pelo tempo de serviço na empresa. Já que $46 \%$ dos funcionários possuem mais de dez anos de empresa, infere-se que o tempo de serviço pode ter gerado uma falsa percepção de estabilidade, fazendo com que os funcionários tenham uma postura de resignação no trabalho.

Outras possíveis causas podem estar relacionadas à falta de comprometimento ou desmotivação, que podem gerar resistência até mesmo em empresas com que já tenham procedimentos registrados e que estejam seguindo os requisitos da norma (Nadae, Oliveira \& Oliveira, 2009). Nesse sentido, buscou-se analisar este fator na percepção dos entrevistados.

Observa-se que há uma concordância significativa de $90 \%$ dos funcionários que se dizem satisfeitos com o comprometimento da empresa, enquanto que apenas $8 \%$ não concordam (Tabela 4). A ABNT (2000) destaca que a direção e toda a empresa, mas principalmente a direção, deve fornecer evidência do seu comprometimento com o desenvolvimento e com a manutenção do Sistema de Gestão da Qualidade, para que aconteça realmente uma melhoria continuado nos processos e aumente a eficácia dos resultados, comprovam que a empresa vai a acordo com o que busca a norma.

Tabela 4 - Falta de comprometimento de toda a organização

\begin{tabular}{c|c|c|c|c}
\hline 1 & 2 & 3 & 4 & 5 \\
$\begin{array}{c}\text { Discordo } \\
\text { Completamente }\end{array}$ & Discordo & $\begin{array}{c}\text { Nem Concordo } \\
\text { Nem Discordo }\end{array}$ & Concordo & $\begin{array}{c}\text { Concordo } \\
\text { Completamente }\end{array}$ \\
\hline 23 & 22 & 1 & 1 & 3 \\
$46 \%$ & $44 \%$ & $2 \%$ & $2 \%$ & $6 \%$ \\
\hline
\end{tabular}

Fonte: Elaborado pelos autores, 2019.

Em relação à ansiedade por resultados, foi possível constatar que mais de $60 \%$ dos funcionários concordam que há ansiedade na busca por resultados (Tabela 5), enquanto que $20 \%$ discordam que há esta prática. Miranda (2014) também adverte que é papel da alta direção elaborar um projeto adequado que possibilite a eliminação da ansiedade quanto à obtenção de resultados imediatos após a implantação do referido sistema.

Tabela 5 - Ansiedade por resultados

\begin{tabular}{c|c|c|c|c}
\hline 1 & 2 & 3 & 4 & 5 \\
$\begin{array}{c}\text { Discordo } \\
\text { Completamente }\end{array}$ & Discordo & $\begin{array}{c}\text { Nem Concordo } \\
\text { Nem Discordo }\end{array}$ & Concordo & $\begin{array}{c}\text { Concordo } \\
\text { Completamente }\end{array}$ \\
\hline 3 & 7 & 7 & 19 & 14 \\
$6 \%$ & $14 \%$ & $14 \%$ & $38 \%$ & $28 \%$ \\
\hline
\end{tabular}

Fonte: Elaborado pelos autores, 2019.

Para que se obtenha resultados positivos na área produtiva e na rentabilidade das empresas é necessário investir em programas de treinamento e capacitação, seja em aspectos de gestão ou comportamentais (Milan, Pretto \& Pigozzi, 2012). No que tange ao atendimento das especificações das normas de qualidade analisar este processo se torna premente.

De acordo com a percepção dos funcionários (Tabela 6), $82 \%$ avaliaram que a empresa se preocupa com treinamentos, porém 14\% apontam que existe necessidade de maior treinamento. Nesse aspecto, é possível afirmar que a empresa, ao se preocupar com a capacitação do pessoal, procura manter os requisitos da norma, uma vez que a eficácia dos processos será alcançada por meio do treinamento da mão de obra. A norma ISO 9001 exige conhecimento e controle da satisfação de clientes internos e externos, além de treinamento da força de trabalho (Freitas, 2011). 


\begin{tabular}{|c|c|c|c|c|}
\hline $\begin{array}{c}1 \\
\text { Discordo } \\
\text { Completamente }\end{array}$ & $\begin{array}{c}2 \\
\text { Discordo }\end{array}$ & $\begin{array}{c}3 \\
\text { Nem Concordo } \\
\text { Nem Discordo }\end{array}$ & $\begin{array}{c}4 \\
\text { Concordo }\end{array}$ & $\begin{array}{c}5 \\
\text { Concordo } \\
\text { Completamente }\end{array}$ \\
\hline 26 & 15 & 2 & 3 & 4 \\
\hline $52 \%$ & $30 \%$ & $4 \%$ & $6 \%$ & $8 \%$ \\
\hline
\end{tabular}

Fonte: Elaborado pelos autores, 2019.

Quanto à burocratização do processo, como mostra a Tabela 7, 80\% dos funcionários concordaram que a implantação e manutenção do Sistema de Gestão da Qualidade conforme a norma ISO 9001 tornou os processos mais burocráticos e $22 \%$ disseram que discordam. Esse resultado pode ser explicado pela padronização dos processos técnicos e administrativos e com a definição de responsabilidades, mas deve ser levado em consideração que as empresas evitam desperdícios, além de aumentar a produtividade, a qualidade de produtos e aumentar a eficiência produtiva. Entretanto, em primeiro momento, gera a sensação de excessiva burocracia (Maekawa, Carvalho \& Oliveira, 2013).

Tabela 7 - A ISO 9001 tornou o processo mais burocrático

\begin{tabular}{c|c|c|c|c}
\hline 1 & 2 & 3 & 4 & 5 \\
$\begin{array}{c}\text { Discordo } \\
\text { Completamente }\end{array}$ & Discordo & $\begin{array}{c}\text { Nem Concordo } \\
\text { Nem Discordo }\end{array}$ & Concordo & $\begin{array}{c}\text { Concordo } \\
\text { Completamente }\end{array}$ \\
\hline 4 & 7 & 4 & 19 & 16 \\
$8 \%$ & $14 \%$ & $8 \%$ & $38 \%$ & $32 \%$ \\
\hline
\end{tabular}

Fonte: Elaborado pelos autores, 2019.

Quanto à motivação da equipe (Tabela 8), 72\% acreditam que a equipe está motivada. Jogo (2011) em seu estudo em empresas australianas concluiu que a certificação traz motivações internas e produz um efeito positivo no desempenho operacional. Também Jang e Lin (2008) detectaram uma forte correlação positiva entre a implementação da ISO e a motivação da equipe.

Tabela 8 - Equipe desmotivada

\begin{tabular}{c|c|c|c|c}
\hline 1 & 2 & 3 & 4 & 5 \\
$\begin{array}{c}\text { Discordo } \\
\text { Completamente }\end{array}$ & Discordo & $\begin{array}{c}\text { Nem Concordo } \\
\text { Nem Discordo }\end{array}$ & Concordo & $\begin{array}{c}\text { Concordo } \\
\text { Completamente }\end{array}$ \\
\hline 14 & 22 & 10 & 4 & 0 \\
$28 \%$ & $44 \%$ & $20 \%$ & $8 \%$ & $0 \%$ \\
\hline
\end{tabular}

Fonte: Elaborado pelos autores, 2019.

Observa-se que há uma concordância significativa na Tabela 9 quanto à ação da empresa frente a nãoconformidades. Constatou-se que, para 96\% dos funcionários, a empresa procura formas de eliminar as causas da não conformidade que porventura possa aparecer, enquanto $4 \%$ não concordam. 
Tabela 9 - Diante de uma não conformidade a empresa procura descobrir e eliminar as causas

\begin{tabular}{c|c|c|c|c}
\hline 1 & 2 & 3 & 4 & 5 \\
$\begin{array}{c}\text { Discordo } \\
\text { Completamente }\end{array}$ & Discordo & $\begin{array}{c}\text { Nem Concordo } \\
\text { Nem Discordo }\end{array}$ & Concordo & $\begin{array}{c}\text { Concordo } \\
\text { Completamente }\end{array}$ \\
\hline 1 & 1 & 0 & 20 & 80 \\
$2 \%$ & $2 \%$ & $0 \%$ & $40 \%$ & $56 \%$ \\
\hline
\end{tabular}

Fonte: Elaborado pelos autores, 2019.

Não-conformidade, conforme a NBR ISO 9001:2015 é o não atendimento a um requisito pré-estabelecido. Estes requisitos podem variar entre fatores externos e fatores internos (ABNT, 2015). Depois da avaliação da não conformidade, deve-se definir medidas corretivas para eliminar ou minimizar o problema. Quando não se pode eliminar imediatamente, deve-se elaborar um Plano de Ação, com base em ferramentas da Gestão da Qualidade para reduzir os efeitos da não-conformidade.

No estudo, constatou-se também que, para $88 \%$ dos respondentes, os funcionários estão empenhados em não cometer os mesmos erros e apenas $10 \%$ não concordam (Tabela 10).

Tabela 10 - Diante de uma falha que provoca uma não conformidade os funcionários se engajam de forma a não cometerem

\begin{tabular}{c|c|c|c|c}
\hline 1 & 2 & 3 & 4 & 5 \\
$\begin{array}{c}\text { Discordo } \\
\text { Completamente }\end{array}$ & Discordo & $\begin{array}{c}\text { Nem Concordo } \\
\text { Nem Discordo }\end{array}$ & Concordo & $\begin{array}{c}\text { Concordo } \\
\text { Completamente }\end{array}$ \\
\hline 1 & 4 & 1 & 20 & 24 \\
$2 \%$ & $8 \%$ & $2 \%$ & $40 \%$ & $48 \%$ \\
\hline
\end{tabular}

Fonte: Elaborado pelos autores, 2019

Quanto aos indicadores de desempenho (Tabela 11), verificou-se que há uma significativa concordância quanto ao seu uso pela empresa: $96 \%$ dos funcionários concordam que a empresa os utiliza. A escolha dos indicadores de desempenho na construção para atender às normas estabelecidas pela série ISO 9001 precisa ser baseada principalmente na relevância dos processos, devem ser levados em conta de onde vem a maioria das reclamações, quais processos influenciam mais nos resultados e o que é mais importante para os clientes. Entre os indicadores utilizados pela empresa estão: Índice de satisfação do cliente; Manutenção do desempenho do processo produtivo; Redução dos custos de produção e Índices de acidentes.

Tabela 11 - A empresa utiliza indicadores de desempenho para mensurar seus processos

\begin{tabular}{c|c|c|c|c}
\hline 1 & 2 & 3 & 4 & 5 \\
$\begin{array}{c}\text { Discordo } \\
\text { Completamente }\end{array}$ & Discordo & $\begin{array}{c}\text { Nem Concordo } \\
\text { Nem Discordo }\end{array}$ & Concordo & $\begin{array}{c}\text { Concordo } \\
\text { Completamente }\end{array}$ \\
\hline 1 & 1 & 0 & 16 & 32 \\
$2 \%$ & $2 \%$ & $0 \%$ & $32 \%$ & $64 \%$ \\
\hline
\end{tabular}

Fonte: Elaborado pelos autores, 2019.

Em suma podem ser notadas diferentes perspectivas em torno do processo de implantação da ISO 9001 o que não necessariamente implica em concluir que seus preceitos sejam controversos e suas contribuições para a 
eficiência na gestão da qualidade da empresa estejam sendo colocados em cheque. As mudanças dos processos organizacionais implicam em conflitos e divergências antes de serem incorporadas em meio à cultura local. Para minimizar os efeitos danosos deste momento preliminar Bressan (2004) destaca o papel dos gestores que devem favorecer a ocorrência de uma comunicação fluida e ativa, incentivar a participação e compreender as diferenças entre os setores e colaboradores.

\section{Considerações finais}

O desenvolvimento desta pesquisa permitiu compreender como a empresa certificada pelo ISO 9001, obtém vantagens e enfrenta seus desafios. Para tal, tornou-se importante conhecer o funcionamento do Sistema de Gestão da Qualidade da empresa em estudo, avaliar as motivações e os desafios de uma gestão da qualidade pautada nos requisitos da ISO 9001 e, analisar as vantagens obtidas pela empresa ao adotar a certificação ISO 9001.

As vantagens encontradas neste estudo são: o comprometimento e a organização da empresa, treinamento contínuo, envolvimento dos funcionários e a busca por soluções para problemas. Por outro lado, foi possível constatar que os maiores desafios encontrados pela empresa para a manutenção da norma ISO 9001 de 2015, foram: resistência às mudanças por parte dos funcionários; baixa escolaridade dos funcionários; parte da equipe desmotivada; burocratização; maior necessidade de treinamento da equipe e ansiedade por resultados. Estes resultados vão de encontro com os resultados da pesquisa aplicada ao setor de construção a respeito das dificuldades relacionadas à implantação e certificação de sistemas de gestão da qualidade de Depexe e Paladini (2007).

Além disso, os resultados ressaltam a importância da liderança e o quão é importante seu envolvimento para funcionamento do Sistema de Gestão da Qualidade. Também mostra a importância da participação dos colaboradores, na busca por eficiência e melhoria contínua de processos. Bressan (2004) ainda contribui apontando outros elementos como a comunicação e o envolvimento e participação dos colaboradores no processo. A melhoria contínua deve ser uma "filosofia de vida" para a sobrevivência das empresas.

As maiores limitações desta pesquisa foram a existência de poucos trabalhos publicados sobre as dificuldades enfrentadas pelas empresas após a implantação da ISO 9001 e o fato de o instrumento de coleta ter sido aplicado por um funcionário da empresa, o que pode ter gerado insegurança nos demais colaboradores; além, também, de poucas informações disponibilizadas pela empresa. Como estudos futuros sugere-se analisar os fatores que geram resistência pelos colaboradores e o papel dos líderes na reversão deste quadro.

\section{Referências}

ABNT, Associação Brasileira de Normas Técnicas (2000). Sistemas de gestão da qualidade: Fundamentos e vocabulário. NBR ISO 9001. Rio de Janeiro.

ABNT, Associação Brasileira de Normas Técnicas (2015). NBR ISO 14001.Sistemas de gestão ambiental — Requisitos com orientações para uso. Rio de Janeiro: ABNT.

ABNT, Associação Brasileira de Normas Técnicas. (2015). ABNT NBR ISO 9001:2015. Sistema de gestão da qualidade - Requisitos. Rio de Janeiro: ABNT.

Ávila, L. V., \& Stecca, J. P. (2015). Gestão de Pessoas. Santa Maria, RS: UFSM.

Barbosa, S. A. (2013). A Importância da Implantação do Sistema de Gestão da Qualidade: Um Estudo de Caso na Empresa Campo Fertilidade do Solo e Nutrição Vegetal LTDA. Monografia, Paracatu.

Bento, G. M., \& Lucena, R. G. (2017). A importância da Gestão da Qualidade com a implementação da ISO 9001 para o desenvolvimento e melhoria da empresa SOFT com tecnologia. São Paulo: IESP.

Bressan, C. L. (2004). Mudança Organizacional: uma visão gerencial. Seminário de gestão de negócios, 1, 1-14. 
Campos, V. F. (1992). Controle da Qualidade Total - No estilo Japonês. Belo Horizonte: Escola de Engenharia da UFMG/Fundação Christiano Ottoni.

Campos, V. F. (2009). O verdadeiro poder. Nova Lima: INDG Tecnologia e Serviços Ltda.

Cota, Kely Alves, Freitas, M. A. M. de. (2013). Gestão da qualidade, um desafio permanente: um estudo de caso sobre o processo de manutenção de um sistema de qualidade em uma indústria metalúrgica. Produto \& Produção, 14(2). https://doi.org/10.22456/1983-8026.31756.

Depex, M.D, \& Paladini, E.P. (2007). Dificuldades relacionadas à implantação e certificação de sistemas de gestão da qualidade em empresas construtoras. Revista Gestão Industrial, 3(1), 13-25.https:

//doi.org/10.3895/S1808-04482007000100002

Fortes, M. M. (2012). ISO 9001:2008: Roteiro prático para implantação.

Freitas, M. R. (2011). A norma ISO 9000 e o modelo de excelência em gestão garantindo a qualidade na prestação de serviços em uma empresa Junior de consultoria. Trabalho de Conclusão de Curso, Juiz de Fora: UFJF.

Gil, A. C. (2002) Métodos e técnicas de pesquisa social. 5. ed. São Paulo: Atlas.

Guba, E., \& Lincoln, Y. (1981). Effective Evaluation. São Francisco: Jossey-Bass.

IBRAM, Instituto Brasileiro de Mineração (2011). Informações e Análises da Economia Mineral. 6 ed.

Jang, W., \& Lin, C. (2008). An integrated framework for ISO 9000 motivation, depth of ISO implementation and firm performance: The case of Taiwan. Journal of Manufacturing Technology Management, 19(2), 194-216.

Kotler, P., \& Armstrong, G. (2013) Princípios de Marketing. 9. ed. São Paulo: Prentice Hall.

Lage, N. (2019). Lítio: A nova salvação do Vale da Miséria (É mesmo?), Movimento dos Atingidos por Barragens (MAB) Água e energia não são mercadorias!

Lima, D. P. (2018). Princípios básicos da Qualidade Total, Paraná.

Maekawa, R., Carvalho, Marly Monteiro de, \& Oliveira, Otávio José de. (2013). Um estudo sobre a certificação ISO 9001 no Brasil: mapeamento de motivações, benefícios e dificuldades. Gestão \& Produção, 20(4), 763-779. Epub November 05. https://doi.org/10.1590/S0104-530X2013005000003

Marconi, M. de A., \& Lakatos, E. M. (2002). Técnicas de pesquisa: planejamento e execução de pesquisas, amostragens e técnicas de pesquisas, elaboração, análise e interpretação de dados. 5. ed. São Paulo: Atlas.

Marin, P. D. (2012). Sistemas de Gestão da Qualidade e Certificação ISO 9001. Centro de Convenções Ulysses Guimarães Brasília, DF.

Milan, G. S.; Pretto, M. R. \& Pigozzi, P. R. (2012) Gestão da qualidade e cultura organizacional: um estudo de caso desenvolvido em uma fábrica de embalagens de papelão. Revista de Negócios, 17(4), 40-54, out./dez.

Minayo, M.C. de S. (2010). O desafio do conhecimento: Pesquisa Qualitativa em Saúde. 12 ed. São Paulo: Hucitec-Abrasco.

Miranda, F. J. (2014). O impacto da implantação da norma ISO 9001:2008 na gestão de empresas do setor de prestação de serviço. Dissertação de mestrado, Pedro Leopoldo.

Nadae, J. de; Oliveira, J. A. de \& Oliveira, O. J. de. (2009). Um estudo sobre a adoção dos programas e ferramentas da qualidade em empresas com certificação ISO 9001: estudos de casos múltiplos. GEPROS. Gestão da Produção e Operações e Sistemas, 4(4), 93-114, out.-dez.

Paladini, E. P. (2012). Gestão da qualidade: teoria e prática. 3 ed. São Paulo: Editora Atlas.

Paulista, P.H, \& Turrioni, J. B. (2018). Análise do processo de realização de auditoria de sistema de gestão da qualidade: principais problemas. In: ENCONTRO NACIONAL DE ENGENHARIA DE PRODUÇÃO. XVIII., Rio de Janeiro. http://www.abepro.org.br/biblioteca/enegep2008_tn_stp_069_490_11317.pdf.

Reis, E. (1996). Estatística Descritiva. Lisboa: Edições Sílabo.

Rigoni, J. R. (2018). Como manter um Sistema de Gestão da Qualidade - dicas para manutenção do SGQ. Total Qualidade. 
Desafios e oportunidades para manutenção da ISO 9001/2015 em uma empresa de mineração do Vale do Jequitinhonha

Stoner, A. F. (1992). Administração. 5. ed. São Paulo: PHB.

Tanabe, C. H., \& Souza, J. P. (2006). Dificuldades na implantação de um sistema da qualidade baseado na norma 9001. São Paulo, Bauru: XIII SIMPEP.

Vitoreli, G. A., \& Carpinetti, L. C. R. (2013). Análise da integração dos sistemas de gestão normalizados ISO 9001 e OHSAS 18001: estudo de casos múltiplos. Gestão \& Produção, 20(1), 204-217.

https://doi.org/10.1590/S0104-530X2013000100015

Yin, R. K. (2001). Estudo de caso: planejamento e métodos. 2 ed. Porto Alegre: Bookman. 